Titel: Soe rond ommie bos

Outeur: Veronique Jephtas

Uitgewer: Protea Boekhuis, 2021

ISBN:

\title{
"jamme sê betieken fokkol": Veronique Jephtas se Soe rond ommie bos (2021)
}

Die debuutbundel van Veronique Jephtas, Soe rond ommie bos (2021), maak behoorlik amok met protespoësie wat uitdruklik sê: daar is fout met die samelewing! Reeds in die openingsgedigte "uyinene mrwetyana" (8) wat oorloop in "die man wattie koeie melk" (9) staan die pejoratiewe van rassediskriminasie voorop wanneer die spreker haarself voorstel as 'n "meid mette warme bôs", en by herhaling, met behulp van 'n interne sintaktiese afwyking binne 'n parallelisme, 'n "meid yt Stellenbos". Hierin gebruik sy nie net 'n skeldnaam "meit" om haarself voor te stel nie, maar stel ook haarself as "maid" (of huishulp) voorop in die aangesig van wit mense:

soe rond ommie bos

my tong skiet los

ek praat ytie mond vanne meid mette warme bôs

ek praat ytie oegpunt vanne maid yt Stellenbos

'n Lang aanhaling uit James Baldwin se Of Beale Street could Talk word gebruik as die motto tot die bundel. Hierin gaan dit oor "the root of resentment", wat onder andere te make het met dit wat 'n man se verbeelding oor 'n vrou maak, en hoe 'n vrou daaraan uitgelewer is. Hiermee kom aspekte van patriargie en seksisme aan bod, wat tesame met rassediskriminasie en wit bevoordeling gesien word as die belangrikste temas van die digbundel.

Die bundel bestaan uit drie afdelings. Die eerste, getiteld "mettie wysheid wat nawete bring", kyk die spreker as born free terug op haar grootwordjare. Die eerste versreëls van gedigte lees baie maal soos volg: "in my kinnerjare" (12) of "ek was sieke soe siewe of agt gewies" (13) of "toe ek gebore was" (14), wat telkens die narratiewe vanuit 'n agternaperspektief vertel met kommentaar vanuit die hede.

Die tema van die afwesige vadersfiguur, waarna die spreker as "sperm donor" (bl. 15 en 18) verwys kan gelees word as 'n knoop in die psige van die digterlike "ek". 'n Insident waar 'n rower die spreker se ouma by 'n OTM besteel, maar gevang word en pleit dat haar ouma nie 'n saak maak nie, lê 'n belangrike karaktertrek van die digter as eenheidsfiguur in die bundel voor: "is dai dag toe ek my grootste character trait komeet/ ek hettie dai jong jamme gekry nie/ jamme sê betieken fokkol".

'n Sterk gevoel vir dit wat reg en wat verkeerd is, word as karaktertrek van die spreker onthul in "man staan" (19). Hier vertel sy hoe 'n onderwyser 'n leerling te na kom in die klas; later word die onderwyser pastoor: "maa ek het gewiet wattie menee nou doen is vekeed/ hy is vandag 'n pastor/ en ek was lanklaas innie kêk". Te midde van die jeugwêreld se onregte is ouma se "vyeboem" (21) 'n toevlug: 


\section{vyeboem}

in my ouma se jaat

was 'n moerse vyeboem

somehow

wanne ek emotional geraak het

het ek innie vyeboom gan hyl

die boem was groot

ek was hoeg

en net virre paa miniete wassit moontlik

om weg te kô van alles

Die tweede afdeling heet "issie 'n cycle nie, is life", wat groter maatskaplike probleme aan die hand van gewone mense se lewens belig. Armoede, siekte, prostitusie, drankmisbruik en geslagsgebaseerde geweld, is enkele kwessies wat meer as een maal in hierdie afdeling aan bod kom. In "mandela se legacy" (31) sê die spreker sardonies: "kyk wat het mandela vi antie gerty gelos/ geld vi wyn/ die system wêk nog once/ en al waamee antie gerty nou sit -/ is vyf empties en fokkol om te vriet". Van geslagsgebaseerde geweld skryf sy in "lizzy, baby" (37): "lizzy postie anne dag op facebook my oukie slaan my/ lizzy het nou 'n baba van die oukie/ ná sy so perform het op facebook/ sy was nog altyd lus virrie abusive tollie/ wan al wiet ôs mense daa is biete sal hulle bly waarit gemaklik is/ vi nou".

Die sterkste verse kom in die derde afdeling na vore, getiteld "hie rukkie ding". Telkens spreek die digter haar woede uit teenoor wit mense, wat hulself as superieur teenoor bruin en swart mense gedra. Jephtas kry dit reg om te praat oor ongemaklike dog noodsaaklike rassekwessies. Hierin kan die titel ironies verstaan word, want Jepthas loop beslis nie "soe rond ommie bos" nie, maar is prontuit en op die man af - vergelyk "ôs wil oek" (43): "susan, ek en jy issie equalie/ jou capitalism en racism en patriarchy wil nettie opraakie/ jou privilege skrie soes jy met geboorte/ my culture issie 'n costumie/ braids isse protective hairstyle not a trend".

Die betekenis van "bos" aktiveer terselfdertyd ook die troop van "black hair politics", wat in "endgame" soos volg aangespreek word:

\section{endgame}

ek sallie eerste een wies om te admit dat met groot hare kô aandag en onnorage baggage

by woordfees 2019 toe gan kyk ek endgame

die een tannie sak af

jy kan nie jou hoë hare maak as jy teater kom kyk nie

ek gie haa toe 'n vylkyk

toe sak sy wee af

ek grap maar net hoor

die sad deel vannie hele storie wassie ees dat sy it gesê hettie dit wassie dat ek kon hoor sy joke genuinely en is uneducated oo hare nie maa it wassie feit dat my wit vrinne vi my sê 
ek kan nie glo sy sê dit vir jou nie, maa hulle sê dittie vi haa nie die tannie wattie kon sienie sit nou op anne mense se seats

en ek sit en dink hoe ek my hare hoër kan maak virrie volgene show

Jephtas dra die bundel op aan "quan en ammel wattie kankers vannie liewe se gat skop". Dié bundel skop hierdie kankers se gat deur maatskaplike kwale behoorlik aan dag te lê. Protes word aangeteken en onreg ten sterkste veroordeel. Jepthas se bundel "is 'n lopende optog", want "sharpville en feesmustfall/ hoe my ma hulle innie fabriek getreat wôd/apartheid/ winnie en my ma en my ouma en ronelda en lee-ann en taren en elmarie en monique en crystal en kay/ en saartjie/ as jy ienage iets wil change moet jy protest jy moetie vullis ytgooi jy moet tyres brand jy moet poems skryf/ al lees nieman mee rêragie".

\section{Alwyn Roux}

Departement Afrikaans en Algemene Literatuurwetenskap, UNISA

E-pos: erouxap@unisa.ac.za 